\title{
Periampullary Region
}

National Cancer Institute

\section{Source}

National Cancer Institute. Periampullary Region. NCI Thesaurus. Code C60699.

The area of the duodenum surrounding the ampulla of Vater. 